\title{
Awareness of emergency contraception
}

\author{
Sarju Mathew, Rennie Urquhart
}

\begin{abstract}
Objective To study the level of awareness and use of emergency contraception (EC) in women attending a pregnancy termination clinic.

Method A questionnaire was handed to all women attending the clinic for termination of pregnancy and related advice during the month of February 2003. Completed questionnaires were collected before the women left the clinic and the data analysed.
\end{abstract}

Results A total of 78 women received the questionnaire and all except two were returned. Fifty-nine (78\%) women were familiar with EC. Sixty percent of women felt that EC was easily accessible, but only $37 \%$ of them had ever used it. However, $90 \%$ of the women questioned would consider using $\mathrm{EC}$ in the future.

Conclusion Despite the level of awareness of EC in Fife being quite good, EC is underused for many reasons.

J Fam Plann Reprod Health Care 2005; 31(2): 113-114

(Accepted 7 October 2004)

\section{Key message points}

- Even though contraception, including the postcoital pill, is freely available, the rate of repeat terminations is high.

- The level of awareness of emergency contraception is quite high, but it is infrequently used.

\section{Introduction}

Emergency contraception (EC) or the morning-after pill is an old concept. Yuzpe's method, ${ }^{1}$ employing a combination of $200 \mu \mathrm{g}$ ethinylestradiol and $2 \mathrm{mg}$ dl-norgestrel, has been widely used for over 20 years since the 1970s. In the UK, this method has been superseded by progestogen-only EC using levonorgestrel (Levonelle $2^{\circledR}$ ). This regimen is better tolerated and more effective than the Yuzpe regimen. ${ }^{2}$ Even though contraception, including the postcoital pill, is freely available, the rate of repeat termination is high. In Fife, $25 \%$ of those who have undergone termination of pregnancy (TOP) will return for a repeat TOP. ${ }^{3}$

The objective of the present study was to investigate the level of awareness and use of EC in women attending a pregnancy termination clinic.

\section{Methods}

The study was conducted in the pregnancy termination clinic at Forth Park Hospital in Kirkcaldy where all women requesting pregnancy termination are seen and counselled. About 1000 women are seen annually at this clinic, which serves a population of 300000 . As the study did not involve any personal data collection, there were no consent issues and therefore ethical committee clearance was not required

Forth Park Hospital, Kirkcaldy, UK

Sarju Mathew, MD, MRCOG, Specialist Registrar in Obstetrics and Gynaecology

Rennie Urquhart, MD, FRCOG, Consultant Obstetrician and

Gynaecologist

Correspondence to: Dr S Mathew, The Simpson Centre for Reproductive Health, 51 Little France Crescent, New Royal Infirmary of Edinburgh, Edinburgh EH16 4SA, UK

E-mail: doctorsarjumathew@hotmail.com
A questionnaire (Figure 1) was prepared to assess the level of awareness and use of EC. All women attending the TOP clinic during February 2003 were asked to complete the questionnaire whilst at the clinic.

\section{Results}

A total of 78 women received the questionnaire. All except two of them returned the completed questionnaire. All calculations and comparisons were done on the 76 completed questionnaires. Fifty-nine (78\%) women were familiar with the terms "emergency contraception, postcoital contraception or morning-after pill'. The majority of the women could list at least two sources of EC (Table 1). The commonest sources of EC listed were doctors (68\%), chemists (43\%) and family planning clinics (20\%).

Sixty percent of the women felt that EC was easy to access (Figure 2). Despite this, only $37 \%$ of the study group had ever used EC. Knowledge about the time limit of EC effectiveness was good. Fifty-nine percent knew about the 72-hour window of effectiveness. Only 4/76 (5\%) women had used EC during their current pregnancy. Ninety percent of women would, however, use EC in the future.

\section{Discussion}

Despite easy availability of contraception, the number of TOP procedures performed is rising. There are many reasons for this including poor compliance, lack of motivation, method failure and changes in social

\section{PATIENT AWARENESS AND USE OF POSTCOITAL CONTRACEPTION (PCC)}

We would be grateful if you could spend a few minutes while waiting to see the nurse/doctor filling up this form. We are interested to find out about women's knowledge, attitude and use of POSTCOITAL CONTRACEPTION (also known as EMERGENCY CONTRACEPTION or MORNING AFTER PILL).

This is a tablet you swallow which will prevent pregnancy in 9 times out of 10 in cases of burst condom, etc.

1 Have you heard of postcoital contraception? If no go to Question 8.

YES/NO

2 Where would you get it from? (List as many places as you know)

3 How long after sex is it effective in preventing pregnancy? (Please circle your answer)

$0-24$ hours

$0-48$ hours

$0-72$ hours

Up to 1 week

Don't know

4 Have you ever used postcoital contraception? YES/NO

5 Did you use it in this pregnancy?

6 If yes (in this pregnancy) where did you get it from?

7 How easy is it to get hold of? (Please circle your answer) Very easy

Easy

Difficult

Very difficult

Don't know

8 If in the future you find yourself at risk of pregnancy e.g. burst condom), would you consider taking POSTCOITAL CONTRACEPTION?

YES/NO

Figure 1 Questionnaire used in the present study 
ARTICLE

Table 1 Sources of emergency contraception identified by the study participants

\begin{tabular}{lll}
\hline Source of emergency contraception & Total $(n)$ & $\%$ \\
\hline Doctor & 52 & 68 \\
Chemist & 33 & 43 \\
Family planning clinic & 15 & 20 \\
Clinics & 7 & 9 \\
Well-woman clinic & 5 & 6 \\
Accident and emergency department & 3 & 4 \\
Hospital & 7 & 9 \\
Breast clinic & 1 & 1 \\
Genitourinary medicine clinic & 3 & 4 \\
\hline
\end{tabular}

circumstances as suggested by previous studies. ${ }^{4-6}$ Use of EC within 72 hours of unprotected coitus can reduce unwanted pregnancy by $75 \% .{ }^{4}$ Levonelle 2 is a widely used method in the UK with a $1.1 \%$ failure rate. ${ }^{2}$ Twenty-two percent of women in the present study were totally unaware of postcoital contraception. Despite the majority of them having knowledge of EC, only 5\% had used it in their current pregnancy.

Although $60 \%$ felt that EC was quite easily available, only $37 \%$ had ever used it. It is apparent from this study that despite adequate knowledge, the majority of women for various reasons did not use EC. Concerns about the side effects of the oral contraceptive pill (recent 'pill scares') may have 'spilled over' and affected women's perception of EC. Though EC is available easily over the counter without prescription, it is expensive and this could be another limiting factor regarding its use.

Possible solutions could be easier accessibility, cost reduction, education in schools and through appropriate use of the media. Glasier and Baird, in a study published in 1998,5 concluded that making EC more easily available does no harm and may reduce the rate of unwanted pregnancies. This study recommended that women have a supply of EC in the bathroom cabinet. Free et al..$^{6}$ studied the attitude of women aged 16-25 years from socially deprived inner city areas of London towards EC and concluded that these young women were less able or willing than others to take advantage of recent improvements in access to EC. As regards the present study, it wasn't possible to reach any conclusions of this type as the study's specific aim was to assess knowledge of EC in a local population and it was felt that the shorter and simpler the questionnaire, the greater the likelihood of patient participation. The most reassuring aspect of the data obtained from the present study was that $90 \%$ of those women who responded to the questionnaire would be willing to use EC in the future, although intent does not always translate into action.

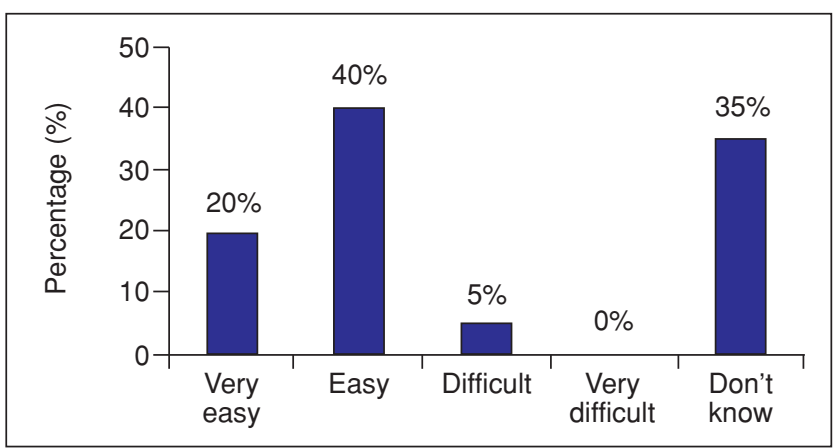

Figure 2 Study participants' opinions on the availability of emergency contraception

\section{Conclusions}

The present study demonstrated that the level of awareness, knowledge of availability and effectiveness of EC in Fife is quite high (78\%), but that, in practice, $\mathrm{EC}$ is infrequently used. Larger studies looking into the factors limiting the use of EC, comprising samples from different socioeconomic classes and ethnic backgrounds, could help to improve our understanding of why women don't use this effective method of contraception. It may then be possible to develop strategies to increase EC usage and decrease TOP rates.

Statements on funding and competing interests

Funding. None identified.

Competing interests. None identified.

References

1 Yuzpe AA, Lancee WJ. Ethinylestradiol and dl-norgestrel as a postcoital contraceptive. Fertil Steril 1977; 28: 932-936.

2 Randomised controlled trial of levonorgestrel versus Yuzpe regimen of combined oral contraceptives for emergency contraception. World Health Organization Task Force on Post-ovulatory Methods of Fertility Regulation. Lancet 1998; 352: 428-433.

3 Abortions performed in Scotland and in Fife: 2000 and 2002. Source: Notifications (to the Chief Medical Officer for Scotland) of abortions performed under the Abortion Act 1967. Ref. IR2004-00800. Information and Statistics Division Scotland. http://www.isdscotland. org/isd.

4 Glasier A. Emergency contraception. Best Pract Res Clin Obstet Gynaecol 2002; 16: 181-191.

5 Glasier A, Baird D. The effects of self-administering emergency contraception. N Engl J Med 1998; 339: 1-4.

6 Free C, Lee RM, Ogden J. Young women's accounts of factors influencing their use and non-use of emergency contraception. $B M J$ 2002; 325: 1393-1396.

\section{ASSOCIATE MEMBERSHIP OF THE FFPRHC FOR NURSES}

Associate membership of the Faculty of Family Planning and Reproductive Health Care is open to all nurses with a special interest in contraception and reproductive health. The annual subscription is currently $£ 40$. This subscription entitles Associate Members to copies of the Journal of Family Planning and Reproductive Health Care and access to the members' enquiry service.

The associate membership application form can be obtained from the Faculty website at www.ffprhc.org.uk (click on General Training/Training Form). 